\title{
Hardwired synthetic lethality within the cohesin complex in human
}

\section{cancer cells}

Petra van der Lelij ${ }^{*}$, Simone Lieb $^{2^{*}}$, Julian Jude ${ }^{1}$, Gordana Wutz ${ }^{1}$, Catarina P. Santos ${ }^{3}$, Katrina Falkenberg ${ }^{1}$, Andreas Schlatt| ${ }^{2}$, Jozef Ban ${ }^{4}$, Raphaela Schwentner ${ }^{4}$, Heinrich Kovar ${ }^{4,5}$, Francisco X. Real $^{3,6}$, Todd Waldman ${ }^{7}$, Mark A. Pearson ${ }^{2}$, Norbert Kraut ${ }^{2}$, Jan-Michael Peters ${ }^{1}$, Johannes Zuber ${ }^{1}$ and Mark Petronczki ${ }^{2 \#}$

${ }^{1}$ Research Institute of Molecular Pathology (IMP), Vienna Biocenter (VBC), Campus-Vienna-Biocenter 1, 1030 Vienna, Austria

${ }^{2}$ Boehringer Ingelheim RCV, Dr. Boehringer Gasse 5-11, 1121 Vienna, Austria

${ }^{3}$ Spanish National Cancer Research Centre, Melchor Fernández Almagro 3, 28029 Madrid, Spain

${ }^{4}$ Children's Cancer Research Institute, Zimmermannplatz 10, 1090 Vienna, Austria

${ }^{5}$ Department for Pediatrics, Medical University of Vienna, Spitalgasse 23, 1090 Vienna, Austria

${ }^{6}$ Department de Ciències Experimentals I de la Salut, Universitat Pompeu Fabra, Doctor Aiguader 88, 08003

Barcelona, Spain

${ }^{7}$ Lombardi Comprehensive Cancer center, Georgetown University School of Medicine, 3970 Reservoir Road NW, NRB E304, Washington, D.C., USA

*These authors contributed equally to this work

\#Corresponding author: mark_paul.petronczki@boehringer-ingelheim.com

Keywords: cohesin, cancer, synthetic lethality, chromosomes, precision medicine 


\begin{abstract}
Recent genome analyses have identified recurrent mutations in the cohesin complex in a wide range of human cancers. Here we demonstrate that the most frequently mutated subunit of the cohesin complex, STAG2, displays a strong synthetic lethal interaction with its paralog STAG1. Mechanistically, STAG1 loss abrogates sister chromatid cohesion in STAG2 mutated but not in wild-type cells leading to mitotic catastrophe, defective cell division and apoptosis. STAG1 inactivation inhibits the proliferation of STAG2 mutated but not wild-type bladder cancer and Ewing sarcoma cell lines. Restoration of STAG2 expression in a mutated bladder cancer model alleviates the dependency on STAG1. Thus, STAG1 and STAG2 act redundantly to support sister chromatid cohesion and cell survival. STAG1 represents a hardwired, context independent vulnerability of cancer cells carrying mutations in the major emerging tumor suppressor STAG2. Exploiting synthetic lethal interactions to target recurrent cohesin mutations in cancer, e.g. by inhibiting STAG1, holds the promise for the development of selective therapeutics.
\end{abstract}




\section{Main text}

Cohesin is a highly conserved ring-shaped protein complex that is thought to topologically embrace chromatid fibers (Peters \& Nishiyama, 2012), which is essential for sister chromatid cohesion and chromosome segregation in eukaryotes. In addition, cohesin participates in DNA repair, genome organization and gene expression (Losada, 2014). The cohesin subunits SMC1, SMC3 and RAD21 (also called SCC1) comprise the core ring of the complex. A fourth universally conserved subunit, a HEAT repeat protein of the Scc3/STAG family, peripherally associates with the core cohesin ring by binding to RAD21 (Toth et al., 1999), and is required for the dynamic association of cohesin with chromatin (Hu et al., 2011; Murayama \& Uhlmann, 2014). Human somatic cells express two paralogs of this protein, called STAG1 and STAG2 (Losada, Yokochi, Kobayashi, \& Hirano, 2000; Sumara, Vorlaufer, Gieffers, Peters, \& Peters, 2000).

Recent cancer genome studies identified recurrent mutations in cohesin subunits and regulators in approximately $7.3 \%$ of all human cancers (Lawrence et al., 2014; Leiserson et al., 2015; Solomon et al., 2011). STAG2, the most frequently mutated cohesin subunit, emerges as one of only 12 genes that are significantly mutated in 4 or more major human malignancies (Lawrence et al., 2014). STAG2 mutations have been reported in $\sim 6 \%$ of acute myeloid leukemias and myelodysplastic syndromes (Kon et al., 2013; Thota et al., 2014; Walter et al., 2012), 15-22\% of Ewing's sarcomas (Brohl et al., 2014; Crompton et al., 2014; Tirode et al., 2014), and in up to 26\% of bladder cancers of various stages and grades (Balbas-Martinez et al., 2013; Guo et al., 2013; Solomon et al., 2013; Taylor, Platt, Hurst, Thygesen, \& Knowles, 2014). The deleterious nature of most STAG2 mutations strongly suggests that the gene represents a new tumor suppressor (Hill, Kim, \& Waldman, 2016). STAG2 mutations were initially thought to promote tumorigenesis due to defects in sister chromatid cohesin leading to genome instability (Barber et al., 2008; Solomon et al., 2011). However, the vast majority of cohesin-mutated cancers are euploid (Balbas-Martinez et 
al., 2013; Kon et al., 2013), indicating that cohesin mutations may promote tumorigenesis through altering different cohesin functions such as genome organization and transcriptional regulation (Galeev et al., 2016; Mazumdar et al., 2015; Mullenders et al., 2015; Viny et al., 2015). Regardless of the mechanisms driving cohesin mutant tumors, the recent success of poly(ADP-ribose) polymerase inhibitors in the treatment of BRCA-mutated ovarian and prostate cancer demonstrates that exploiting tumor suppressor loss by applying the concept of synthetic lethality in defined patient populations can impact clinical cancer care (Castro, Mateo, Olmos, \& de Bono, 2016; G. Kim et al., 2015; Mirza et al., 2016; Oza et al., 2015). The estimated half a million individuals with STAG2mutant malignancies would greatly profit from exploring specific dependencies of these cancers.

We hypothesized that STAG2 loss could alter the properties and function of the cohesin complex leading to unique vulnerabilities of STAG2 mutated cells. To identify factors whose inactivation would be synthetic lethal with loss of STAG2 function, we first used CRISPR/Cas9 to inactivate STAG2 in near-diploid, chromosomally stable HCT 116 colon carcinoma cells (Figure 1A). Two clones, STAG2- 505c1 and 502c4, harboring deleterious mutations in STAG2 and lacking detectable STAG2 protein expression were selected for analyses (Figure supplement 1). The isogenic parental and STAG2- HCT 116 cells were transfected with short-interfering RNA (siRNA) duplexes targeting 25 known cohesin subunits and regulators. After normalization to the non-target control siRNA (NTC), the effects of siRNA duplexes targeting individual genes were compared in parental and STAG2- cells. Depletion of the known essential cohesin regulator SGOL1, had a detrimental impact on viability of both parental and STAG2- cells. Remarkably, depletion of STAG1 strongly decreased cell viability in STAG2- cells, while being tolerated by the isogenic parental cells (Figure 1B). The pronounced selective effect of STAG1 depletion on STAG2- cells was confirmed in individual transfection experiments and colony formation assays (Figure 1C,D,E). Expression of an siRNA-resistant STAG1 transgene alleviated the anti-proliferative effect of STAG1 but not of SGOL1 siRNA duplexes in STAG2- HCT 116 cells demonstrating the specificity of the siRNA 
treatment (Figure supplement 2). Double depletion of STAG1 and STAG2 by siRNA in parental cells confirmed their synthetic lethal interaction (Figure supplement 3A). Co-depletion of p53 and STAG1 indicated that the dependency of STAG2- cells on STAG1 was independent of p53 (Figure supplement 3B). To corroborate these findings using an independent strategy, we introduced Cas9 into parental and STAG2- HCT 116 and KBM-7 leukemia cells for competition assays (Figure 1F; Figure supplement 1). Transduction of lentiviruses co-expressing mCherry and single guide RNAs (sgRNAs) targeting essential cohesin subunit genes, such as RAD21 and SMC3, resulted in the rapid loss of the infected and mCherry-positive cells from the population irrespective of STAG2 genotype (Figure 1F). In striking contrast, transduction with sgRNAs targeting STAG1 caused the depletion of STAG2- HCT 116 and KBM-7 cells but not of their parental STAG2 proficient counterparts (Figure 1F). Collectively, these experiments identify STAG1 as a vulnerability of STAG2 mutated cells in engineered solid cancer and leukemia models. STAG1 inactivation has little if any impact on the viability and proliferation of wild-type cells, but is essential for survival in the absence of STAG2.

To elucidate the mechanistic basis for this synthetic lethal interaction, we hypothesized that the combined loss of STAG1 and STAG2, in contrast to loss of either component alone, could severely impair cell division. Chromosome alignment and segregation during mitosis rely on sister chromatid cohesion, the central function of the cohesin complex(Peters \& Nishiyama, 2012). Depletion of STAG1 resulted in an increase in the mitotic index and a prolongation of the duration of mitosis in STAG2- but not wild-type cells (Figure 2A and Figure supplement 4A). Immunofluorescence microscopy revealed a failure to align chromosomes at the metaphase plate upon STAG1 loss in STAG2- cells (Figure 2B). In mitotic chromosome spread analysis STAG2 inactivation caused a partial loss of centromeric cohesion in HCT 116 cells as previously reported (Canudas \& Smith, 2009; J. S. Kim et al., 2016; Remeseiro et al., 2012; Solomon et al., 2011) (Figure 2C). Depletion of the essential centromeric cohesin protection factor SGOL1 resulted in a complete loss of sister 
chromatid cohesion in most chromosome spreads irrespective of STAG2 genotype. In striking contrast, STAG1 depletion selectively abrogated sister chromatid cohesion in STAG2- but not parental cells (Figure 2C, single chromatids). The severe mitotic defects observed upon loss of STAG1 in STAG2- cells were accompanied by the emergence of aberrantly sized and shaped interphase nuclei (Figure supplement 4B) and by a progressive increase in apoptosis (Figure 2D). These results provide a mechanistic basis for the synthetic lethal interaction between STAG1 and STAG2. STAG1 inactivation abrogates sister chromatid cohesion exclusively in STAG2- cells resulting in catastrophic mitotic failure, abnormal cell division and apoptosis. To hold sister chromatids together, cohesin can tolerate the loss of either STAG1 or STAG2 alone but not the loss of both.

We next expanded our analysis to patient-derived STAG2 mutations and STAG2-mutant cancer cell lines in order to investigate the disease relevance of the observed synthetic lethality. STAG1 depletion by siRNA abrogated both cell viability and sister chromatid cohesion in HCT 116 cell clones, in which three patient-derived deleterious mutations had been engineered into the STAG2 locus (J. S. Kim et al., 2016), but not in parental HCT 116 cells (Figure supplement 5). Among solid human cancers, STAG2 mutational inactivation is most prevalent in urothelial bladder cancer and Ewing sarcoma. Therefore, we assembled a panel of 16 bladder cancer cell lines: 11 STAG2positive, 3 with deleterious STAG2 mutations (UM-UC-3, UM-UC-6 and VM-CUB-3), one in which STAG2 was inactivated by CRISPR/Cas9 (UM-UC-5 STAG2- 505c6) (Figure supplement 1), and two with no detectable STAG2 expression (LGWO1 and MGH-U3) (Table supplement 1) (BalbasMartinez et al., 2013; Solomon et al., 2013). The STAG2 protein expression status in the panel of bladder cancer cell lines was confirmed using immunoblotting (Figure 3A). siRNA experiments revealed that STAG2 status represented a predictive marker for the sensitivity to STAG1 depletion across the bladder cancer cell line panel. Whereas all cell lines were highly sensitive to depletion of the key mitotic kinase PLK1, STAG1 siRNA reduced cell viability in STAG2-negative bladder 
cancer cells but had little or no effect on STAG2-positive bladder cancer cell lines (Figure 3B). STAG1 depletion prevented colony formation and abolished sister chromatid cohesion selectively in STAG2 mutated UM-UC-3 (F983fs) but not in STAG2 wild-type UM-UC-5 bladder cancer cells (Figure 3C,D). In contrast, SGOL1 depletion abrogated cell growth and cohesion in both cell lines. Consistent with the results obtained in bladder cancer cells, STAG2 mutation status also positively correlated with STAG1 dependency in a panel of four Ewing sarcoma cell lines (Figure 3E,F and Table supplement 1) (Solomon et al., 2011; Tirode et al., 2014). Lentiviral transduction of a FLAGSTAG2 transgene into STAG2 mutated UM-UC-3 bladder cancer cells resulted in the restoration of STAG2 expression, nuclear localization of the transgenic protein and its incorporation into the cohesin complex (Figure supplement 6A-C). Crucially, restoration of STAG2 expression alleviated the STAG1 dependency of UM-UC-3 cells providing a causal link between STAG2 loss and STAG1 dependency (Figure 3G). These results demonstrate that the synthetic lethal interaction between STAG1 and STAG2 that we discovered in isogenic cell pairs is recapitulated in disease-relevant bladder cancer and Ewing sarcoma cell models.

We here identify STAG1 as a strong genetic vulnerability of cells lacking the major emerging tumor suppressor STAG2 (Figure supplement 6D). The synthetic lethal interaction between STAG1 and STAG2 is observed in isogenic HCT 116 and KBM-7 cells as well as in bladder cancer and Ewing sarcoma cell lines. Thus, the genetic interaction between STAG paralogs is context independent and conserved in three major human malignancies: carcinoma, leukemia and sarcoma. Importantly, the finding that cancer cells harboring deleterious STAG2 mutations remain exquisitely dependent on STAG1 demonstrates that this genetic vulnerability is maintained throughout the process of carcinogenesis and not bypassed by adaptive processes, such as the transcriptional activation of the germline-specific paralog STAG3 (Pezzi et al., 2000; Prieto et al., 2001). 
Our experiments strongly suggest that the loss of sister chromatid cohesion followed by aberrant cell division and cell death is the mechanistic basis underlying the synthetic lethality between STAG1 and STAG2 (Figure supplement 6D). Both paralogs associate with the cohesin complex in a mutually exclusive manner (Losada et al., 2000; Sumara et al., 2000). Although STAG1 and STAG2 may confer distinct functionalities to the cohesin complex (Canudas \& Smith, 2009; Remeseiro et al., 2012), STAG1 and STAG2 containing complexes act redundantly to ensure sister chromatid cohesion and successful cell division in human somatic cells. While loss of one paralog is compatible with cell viability and proliferation, the loss of both paralogs abrogates cohesin's ability to hold sister chromatids together, which results in lethality. The fact that STAG1 inactivation has little or no effect on proliferation of STAG2 proficient cells indicates that selective targeting of STAG1 could offer a large therapeutic window. Potential approaches for therapeutic targeting of STAG1 include the inhibition of the interaction between STAG1 and the cohesin ring subunit RAD21 (Hara et al., 2014) and the selective degradation of STAG1 using proteolysis-targeting chimera (PROTAC) technology (Deshaies, 2015). The mechanisms by which mutations in STAG2 and other cohesin subunits drive tumorigenesis in solid and hematological tissues are not yet firmly established. Our work highlights the fact that such knowledge is not a prerequisite for the identification of selective vulnerabilities.

Both deleterious STAG2 mutations and the loss of STAG2 expression are strong predictive biomarkers for STAG1 dependence and could be utilized for patient stratification. Our work demonstrates that unique genetic dependencies of cohesin mutated cancer cells exist. Such vulnerabilities hold the promise to develop selective treatments for patients suffering from STAG2 mutated cancer. 


\section{Author contributions}

P.vdL. and S.L. performed most of the experiments, J.J. and K.F. performed KBM-7 experiments, G.W. performed initial HCT 116 experiments, J.B., R.S. and H.K. performed Ewing sarcoma experiments, C.P.S. and F.X.R. profiled bladder cancer cell lines, A. S. provided bioinformatic support, T.W. provided HCT 116 patient mutation cell lines, S. L., M. A. P., N.K., P.vdL., J-M.P., J.Z. and M.P. designed the project and experiments, P.vdL. and M.P. wrote the manuscript. P.vdL., H.K., F.X.R., T.W., M.A.P., N.K., J-M.P., J.Z. and M.P. edited the manuscript. M.P. conceived and supervised the study.

\section{Acknowledgements}

We would like to thank Monika Kriz and Renate Schnitzer for clonal analysis. The IMP is supported by Boehringer Ingelheim. Research in the laboratory of J-M.P. is funded by the Austrian Science Fund (SFB-F34 and Wittgenstein award Z196-B20) and the Austrian Research Promotion Agency (Headquarter grants FFG-834223 and FFG-852936, Laura Bassi Centre for Optimized Structural Studies grant FFG-840283). Research in the laboratory of J.Z. was funded by a Starting Grant of the European Research Council (ERC no. 336860) and SFB grant F4710 of the Austrian Science Fund (FWF). Research on Ewing sarcoma in the laboratory of H.K. was funded by the Austrian Science Fund ERA-Net grant I 1225-B19. Work in the lab of F.X.R. was funded by a grant from Fundación Científica de la Asociación Española Contra el Cáncer, Madrid, Spain. Research in the laboratory of T.W. is supported by National Institute of Health grant R01CA169345 and an Innovation Grant from Alex's Lemonade Stand.

\section{Competing financial interests}

S.L., A.S., M.A.P., N.K. and M.P. are employees of Boehringer Ingelheim RCV. 


\section{Materials and Methods}

Antibodies. The following antibodies were used: C-term. pAb goat anti-STAG2 (Bethyl, A300-158A and A300-159A), N-term. mAb rabbit anti-STAG2 (Cell Signaling, 5882), full length pAb rabbit antiSTAG2 (Cell signaling, 4239), mouse anti-GAPDH (Abcam, ab8245), rabbit anti-STAG1 (Genetex, GTX129912), mouse anti-FLAG (Sigma, F3165 and F1804), mouse anti-p53 (Calbiochem, OP43), rabbit anti-H3pS10 (Millipore, 06570), FITC Conjugated mouse anti-Tubulin (Sigma, F2168), rabbit anti-SGOL1 (Peters laboratory ID A975M), SMC3 (Peters laboratory ID 845), mouse anti-RAD21 (Millipore, 05-908), rabbit anti-SMC1 (Bethyl A300-055A), and secondary rabbit (P0448), mouse (P0161) and goat (P0160) anti-lgG-HRP (all Dako).

CRISPR/Cas9 and cDNA transgene vectors. The following lentiviral vectors were used to introduce mutations in STAG2 in HCT 116 and UM-UC-5 cells: CRISPR STAG2 Hs0000077505_U6gRNA-Cas9-2A-GFP and CRISPR STAG2 Hs0000077502_U6gRNA-Cas9-2AGFP (Sigma), CRISPR sgRNA STAG2_16 and sgRNA STAG2_19 were co-expressed from U6gRNA 16-U6gRNA 19-EF1as-Thy1.1-P2A-neo to introduce mutations in STAG2 in KBM-7 cells. HCT 116 stably expressing Cas9-GFP were obtained by lentiviral transduction with pLentiCRISPREF1as-Cas9-P2A-GFP-PGK-puro. KBM-7 infected with dox-inducible Cas9 were obtained by sequential retroviral transduction with pWPXLd-EF1A-rtTA3-IRES-EcoRec-PGK-Puro and pSINTRE3G-Cas9-P2A-GFP PGK-Blast. pLVX-3xFLAG-STAG1r-IRES-Puro and pLVX-3xFLAGSTAG2r-IRES-Puro lentiviral vectors for siRNA-resistant transgene expression were generated by gene synthesis (GenScript) based on the STAG1 cDNA sequence NCBI NM_005862.2 and STAG2 cDNA sequence NCBI NM_001042749.2 followed by cloning into the parental pLVX vectors (Clontech). Silent nucleotide changes were introduced into the STAG1 and STAG2 coding sequences within the siRNA target sequences to render the transgenes siRNA-resistant. For competition assays, U6-sgRNA-EF1as-mCherry-P2A-neo lentiviral vectors were used. 
sgRNA sequences used in this study.

\begin{tabular}{|l|l|l|}
\hline sgRNA name & Sequence & Use \\
\hline sgRNA 505 & TGGAAAACGAGCCAATGAG & STAG2 inactivation \\
\hline sgRNA 502 & TTTCGACATACAAGCACCC & STAG2 inactivation \\
\hline $\begin{array}{l}\text { sgRNA } \\
\text { STAG2_16 }\end{array}$ & GATTTGAACTTCTTCCACTG & STAG2 inactivation and competition assay \\
\hline $\begin{array}{l}\text { sgRNA } \\
\text { STAG2_19 }\end{array}$ & GGAAAACGAGCCAATGAG & $\begin{array}{l}\text { STAG2 inactivation and competition assay } \\
\text { (control sgRNA KBM-7) }\end{array}$ \\
\hline STAG1_3 & GTCTGACAAACCCGTCAAAA & Competition assay \\
\hline STAG1_18 & GAATCATATAAACAAGACA & Competition assay \\
\hline STAG2_5 & GAACTCCTGCTACAAAAG & Competition assay \\
\hline STAG2_16 & GATTTGAACTTCTTCCACTG & Competition assay \\
\hline RAD21_2 & GATCGTGAGATAATGAGAGA & Competition assay \\
\hline SMC3_9 & GGATGCAAGAGATAAAATGG & Competition assay \\
\hline CTRL & GTAGCGAACGTGTCCGGCGT & Competition assay (control sgRNA HCT 116) \\
\hline
\end{tabular}

Cell culture and lentiviral transduction. HCT 116 cells were cultured in McCoy's 5A w/glutamax medium supplemented with $10 \%$ fetal calf serum (FCS), KBM-7 cells were cultured in IMDM medium supplemented with $10 \%$ FCS, sodium butyrate, L-glutamine and antibiotics (all Invitrogen). Bladder cancer cell lines UM-UC-5, UM-UC-6, UM-UC-18, LGWO1, and MGHU-3 were cultured in DMEM + 10\% FCS w/NEAA, Glutamax and NaPyruvat, 5637, 639-V, 647-V, J82, JMSU-1, KU-1919, RT4 T24, UM-UC-3 and VM-CUB-3 were cultured according to ATCC instructions. All Ewing sarcoma cell lines were cultured in RPMI $+10 \%$ FCS. Stable cell lines were generated by lentiviral transduction by use of one shot LentiX kit (Clontech) followed by puromycin selection (HCT 116: 2 $\mu \mathrm{g} / \mathrm{ml}$, UM-UC-3: $2 \mu \mathrm{g} / \mathrm{ml}$, UM-UC-5: $3 \mu \mathrm{g} / \mathrm{ml}$ ). Sources, STAG2 status and authentication 
information (STR fingerprinting) of cell lines used in this study are provided in Table supplement 1. All cell lines were tested negatively for mycoplasma contamination.

siRNA transfection, cell viability, competition assay and apoptosis assay. For knockdown experiments, cells were transfected with ON-TARGETplus SMARTpool siRNA duplexes (Dharmacon) and the Lipofectamine RNAiMAX reagent according to the manufacturer's instructions (Invitrogen). HCT 116 chromosome spreads, apoptosis assay, immunoblotting, immunofluorescence and live cell imaging experiments were performed using a final siRNA concentration of $20 \mathrm{nM}$. Cell viability and crystal violet staining assays were performed using $10 \mathrm{nM}$ siRNA. Bladder cancer cells were transfected with $10 \mathrm{nM}$ siRNA for cell viability assays, crystal violet staining and chromosome spreads. The UM-UC-3 FLAG-STAG2 cell line was transfected with $20 \mathrm{nM}$ siRNA for immunoblotting. Ewing sarcoma cell lines were co-transfected with $50 \mathrm{nM}$ ON-TARGETplus SMARTpool siRNAs (Dharmacon) plus pRetro-Super (Brummelkamp, Bernards, \& Agami, 2002) using Lipofectamin Plus reagent (Invitrogen). The next day cells were subjected to puromycin $(1 \mu \mathrm{g} / \mathrm{ml})$ selection for 72 hours(Ban et al., 2014), and cultured for two additional days. Viability was determined using CellTiter-Glo (Promega), and by staining with crystal violet (Sigma, HT901). For sgRNA competition assays, Cas9-GFP was expressed constitutively (HCT 116) or was induced by doxycycline addition (KBM-7). mCherry and sgRNAs were introduced by lentiviral transduction. The fraction of mCherry-positive cells was determined at the indicated time points using a Guava easycyte flow cytometer (Millipore) and normalized to the first measurement and sequentially to control sgRNAs (non-targeting for HCT 116 and STAG2_19 for KBM-7). Apoptosis was analyzed using the IncuCyte Caspase-3/7 Apoptosis Assay (Essen BioScience).

Cell extracts for immunoblotting and FLAG-immunoprecipitation. Cell pellets were resuspended in extraction buffer $(50 \mathrm{mM}$ Tris $\mathrm{Cl} \mathrm{pH} 8.0,150 \mathrm{mM} \mathrm{NaCl}, 1 \%$ Nonidet P-40 supplemented with Complete protease inhibitor mix (Roche) and Phosphatase Inhibitor cocktails 
(Sigma, P5726 and P0044)); for Supplementary Figure 1c (KBM-7) and Supplementary Figure 5, pellets were resuspended in $(25 \mathrm{mM}$ Tris- $\mathrm{HCl} \mathrm{pH} 7.5,100 \mathrm{mM} \mathrm{NaCl}, 5 \mathrm{mM} \mathrm{MgCl} 2,0.2 \% \mathrm{NP}-40,10 \%$ glycerol, $1 \mathrm{mM} \mathrm{NaF}$, Complete protease inhibitor mix (Roche), Benzonase (VWR)) and lysed on ice. Lysates were spun down for 10 minutes, followed by FLAG-immununoprecipitation using antiFLAG M2-Agarose Affinity Gel (Sigma) for two hours and washing with lysis buffer. Input lysates and immunoprecipitates were resuspended in SDS sample buffer and heated to $95^{\circ} \mathrm{C}$.

Immunofluorescence, live cell imaging and chromosome spreads. For immunofluorescence, cells were fixed with $4 \%$ paraformaldehyde for 15 min, permeabilized with $0.2 \%$ Triton $X-100$ in PBS for 10 min and blocked with $3 \%$ BSA in PBS containing $0.01 \%$ Triton $\mathrm{X}-100$. Cells were incubated with primary and secondary antibody (Alexa 594, Molecular Probes), DNA was counterstained with Hoechst 33342 (Molecular Probes H3570) and tubulin was sequentially stained with an FITC-conjugated antibody. Coverslips and chambers were mounted with ProLong Gold (Molecular Probes). Images were taken with an Axio Plan2/AxioCam microscope and processed with MrC5/Axiovision software (Zeiss). IncuCyte was used to record live cells, and duration of mitosis was determined by measuring the time from mitotic cell rounding until anaphase onset. Data analysis was performed with Microsoft Excel 2013 and GraphPad Prism 7. Significance levels were quantified using unpaired $t$ test. For chromosome spread analysis, nocodazole was added to the medium for 60 minutes at $100 \mathrm{ng} / \mathrm{ml}$. Cells were harvested and hypotonically swollen in $40 \%$ medium/60\%tap water for $5 \mathrm{~min}$ at room temperature. Cells were fixed with freshly made Carnoy's solution ( $75 \%$ methanol, $25 \%$ acetic acid), and the fixative was changed three times. For spreading, cells in Carnoy's solution were dropped onto glass slides and dried. Slides were stained with $5 \%$ Giemsa (Merck) for 4 minutes, washed briefly in tap water and air dried. For chromosome spread analysis two independent slides were scored blindly for each condition. 
Table supplement 1 . Cell lines used in this study.

\begin{tabular}{|c|c|c|c|c|c|}
\hline Cell line & Cancer & STAG2 status & $\begin{array}{l}\text { Reference for } \\
\text { STAG2 status }\end{array}$ & Source & $\begin{array}{l}\text { STR } \\
\text { confirmed }\end{array}$ \\
\hline HCT 116 parental & Colon & Wild-type & $\begin{array}{l}\text { (Solomon et } \\
\text { al., 2011), this } \\
\text { study }\end{array}$ & ATCC & Yes \\
\hline HCT 116 STAG2- 502c1 & Colon & M255fs (CRISPR KO) & This study & This study & Yes \\
\hline HCT 116 STAG2- 502c4 & Colon & T220fs (CRISPR KO) & This study & This study & Yes \\
\hline HCT 116 S97X & Colon & S97* (engineered) & $\begin{array}{l}\text { (J. S. Kim et } \\
\text { al., 2016) }\end{array}$ & $\begin{array}{l}\text { (J. S. Kim et al., } \\
\text { 2016) }\end{array}$ & Yes \\
\hline HCT 116 I885fs & Colon & I885fs (engineered) & $\begin{array}{l}\text { (J. S. Kim et } \\
\text { al., 2016) }\end{array}$ & $\begin{array}{l}\text { (J. S. Kim et al., } \\
\text { 2016) }\end{array}$ & Yes \\
\hline НСТ 116 Y1142fs & Colon & Y1142fs (engineered) & $\begin{array}{l}\text { (J. S. Kim et } \\
\text { al., 2016) }\end{array}$ & $\begin{array}{l}\text { (J. S. Kim et al., } \\
\text { 2016) }\end{array}$ & Yes \\
\hline KBM-7 parental & Leukemia & Wild-type & This study & Horizon & Yes \\
\hline $\begin{array}{l}\text { KBM-7 STAG2- } \\
16 \_19 \mathrm{c} 12\end{array}$ & Leukemia & P166fs (CRISPR KO) & This study & This study & Yes \\
\hline 5637 & Bladder & Expressed & $\begin{array}{l}\text { (Solomon et } \\
\text { al., 2013) }\end{array}$ & ATCC & Yes \\
\hline $639-V$ & Bladder & Expressed & $\begin{array}{l}\text { (Balbas- } \\
\text { Martinez et al., } \\
\text { 2013) }\end{array}$ & DSMZ & Yes \\
\hline $647-V$ & Bladder & Expressed & $\begin{array}{l}\text { (Solomon et } \\
\text { al., 2013) }\end{array}$ & DSMZ & Ongoing \\
\hline J82 & Bladder & Expressed & $\begin{array}{l}\text { (Solomon et } \\
\text { al., 2013) }\end{array}$ & ATCC & Yes \\
\hline JMSU-1 & Bladder & Expressed & $\begin{array}{l}\text { (Solomon et } \\
\text { al., 2013) }\end{array}$ & DSMZ & Yes \\
\hline KU-19-19 & Bladder & Expressed & $\begin{array}{l}\text { (Solomon et } \\
\text { al., 2013) }\end{array}$ & DSMZ & Ongoing \\
\hline RT4 & Bladder & Expressed & $\begin{array}{l}\text { (Solomon et } \\
\text { al., 2013) }\end{array}$ & ATCC & Yes \\
\hline T24 & Bladder & Expressed & $\begin{array}{l}\text { (Solomon et } \\
\text { al., 2013) }\end{array}$ & ATCC & Yes \\
\hline UM-UC-5 & Bladder & Expressed & $\begin{array}{l}\text { (Balbas- } \\
\text { Martinez et al., } \\
\text { 2013) }\end{array}$ & $\begin{array}{l}\text { H. B. Grossman } \\
\text { (MDACC, Houston) }\end{array}$ & Yes \\
\hline UM-UC-5 wt & Bladder & Expressed & This study & This study & Ongoing \\
\hline UM-UC-18 & Bladder & Expressed & $\begin{array}{l}\text { (Balbas- } \\
\text { Martinez et al., } \\
\text { 2013) }\end{array}$ & $\begin{array}{l}\text { H. B. Grossman } \\
\text { (MDACC, Houston) }\end{array}$ & Yes \\
\hline LGW01 & Bladder & Expression silenced & $\begin{array}{l}\text { (Balbas- } \\
\text { Martinez et al., } \\
\text { 2013) }\end{array}$ & $\begin{array}{l}\text { J. Reeder } \\
\text { (Rochester, New } \\
\text { York) }\end{array}$ & Yes \\
\hline MGH-U3 & Bladder & Expression silenced & $\begin{array}{l}\text { (Balbas- } \\
\text { Martinez et al., } \\
\text { 2013) }\end{array}$ & $\begin{array}{l}\text { F. Radvanyi (Institut } \\
\text { Curie, Paris, } \\
\text { France) }\end{array}$ & Yes \\
\hline UM-UC-5 c6 & Bladder & $\begin{array}{l}\text { R261fs and E262* } \\
\text { (CRISPR KO) }\end{array}$ & This study & This study & Ongoing \\
\hline UM-UC-3 & Bladder & F983fs & $\begin{array}{l}\text { (Solomon et } \\
\text { al., 2013) }\end{array}$ & ATCC & Ongoing \\
\hline UM-UC-6 & Bladder & $\mathrm{R} 305^{*}$ & $\begin{array}{l}\text { (Balbas- } \\
\text { Martinez et al., } \\
\text { 2013) }\end{array}$ & $\begin{array}{l}\text { H. B. Grossman } \\
\text { (MDACC, Houston) }\end{array}$ & Yes \\
\hline VM-CUB-3 & Bladder & S97fs & $\begin{array}{l}\text { (Balbas- } \\
\text { Martinez et al., } \\
\text { 2013; Solomon } \\
\text { et al., 2013) }\end{array}$ & $\begin{array}{l}\text { L. J. Old (Memorial } \\
\text { Sloan-Kettering } \\
\text { Cancer Center, NY) }\end{array}$ & Yes \\
\hline
\end{tabular}


bioRxiv preprint doi: https://doi.org/10.1101/125708; this version posted April 8, 2017. The copyright holder for this preprint (which was not certified by peer review) is the author/funder, who has granted bioRxiv a license to display the preprint in perpetuity. It is made available under aCC-BY 4.0 International license.

\begin{tabular}{|c|c|c|c|c|c|}
\hline A-673 & $\begin{array}{l}\text { Ewing } \\
\text { sarcoma }\end{array}$ & wt & $\begin{array}{l}\text { (Solomon et } \\
\text { al., 2011; } \\
\text { Tirode et al., } \\
\text { 2014) }\end{array}$ & ATCC & Yes \\
\hline TC-71 & $\begin{array}{l}\text { Ewing } \\
\text { sarcoma }\end{array}$ & wt & $\begin{array}{l}\text { (Solomon et } \\
\text { al., 2011; } \\
\text { Tirode et al., } \\
\text { 2014) }\end{array}$ & $\begin{array}{l}\text { Timothy Triche } \\
\text { (Children's Hospital, } \\
\text { Los Angeles) }\end{array}$ & Yes \\
\hline SK-N-MC & $\begin{array}{l}\text { Ewing } \\
\text { sarcoma }\end{array}$ & M1_R546Del & $\begin{array}{l}\text { (Tirode et al., } \\
2014 \text { ) }\end{array}$ & $\begin{array}{l}\text { June Biedler } \\
\text { (Memorial Sloan } \\
\text { Kettering Cancer } \\
\text { Center, NY) }\end{array}$ & Yes \\
\hline TC-32 & $\begin{array}{l}\text { Ewing } \\
\text { sarcoma }\end{array}$ & Y636fs & $\begin{array}{l}\text { (Solomon et } \\
\text { al., 2011) }\end{array}$ & $\begin{array}{l}\text { Timothy Triche } \\
\text { (Children's Hospital, } \\
\text { Los Angeles) }\end{array}$ & Yes \\
\hline
\end{tabular}




\section{References}

Balbas-Martinez, C., Sagrera, A., Carrillo-de-Santa-Pau, E., Earl, J., Marquez, M., Vazquez, M., . . . Real, F. X. (2013). Recurrent inactivation of STAG2 in bladder cancer is not associated with aneuploidy. Nat Genet, 45(12), 1464-1469. doi:10.1038/ng.2799

Ban, J., Aryee, D. N., Fourtouna, A., van der Ent, W., Kauer, M., Niedan, S., . . Kovar, H. (2014). Suppression of deacetylase SIRT1 mediates tumor-suppressive NOTCH response and offers a novel treatment option in metastatic Ewing sarcoma. Cancer Res, 74(22), 6578-6588. doi:10.1158/0008-5472.CAN14-1736

Barber, T. D., McManus, K., Yuen, K. W., Reis, M., Parmigiani, G., Shen, D., . . Hieter, P. (2008). Chromatid cohesion defects may underlie chromosome instability in human colorectal cancers. Proc Natl Acad Sci U S A, 105(9), 3443-3448. doi:10.1073/pnas.0712384105

Brohl, A. S., Solomon, D. A., Chang, W., Wang, J., Song, Y., Sindiri, S., . . Khan, J. (2014). The genomic landscape of the Ewing Sarcoma family of tumors reveals recurrent STAG2 mutation. PLoS Genet, 10(7), e1004475. doi:10.1371/journal.pgen.1004475

Brummelkamp, T. R., Bernards, R., \& Agami, R. (2002). A system for stable expression of short interfering RNAs in mammalian cells. Science, 296(5567), 550-553. doi:10.1126/science.1068999

Canudas, S., \& Smith, S. (2009). Differential regulation of telomere and centromere cohesion by the Scc3 homologues SA1 and SA2, respectively, in human cells. J Cell Biol, 187(2), 165-173. doi:10.1083/jcb.200903096

Carette, J. E., Guimaraes, C. P., Varadarajan, M., Park, A. S., Wuethrich, I., Godarova, A., . . Brummelkamp, T. R. (2009). Haploid genetic screens in human cells identify host factors used by pathogens. Science, 326(5957), 1231-1235. doi:10.1126/science.1178955

Castro, E., Mateo, J., Olmos, D., \& de Bono, J. S. (2016). Targeting DNA Repair: The Role of PARP Inhibition in the Treatment of Castration-Resistant Prostate Cancer. Cancer J, 22(5), 353-356. doi:10.1097/PPO.0000000000000219

Crompton, B. D., Stewart, C., Taylor-Weiner, A., Alexe, G., Kurek, K. C., Calicchio, M. L., . . Stegmaier, K. (2014). The genomic landscape of pediatric Ewing sarcoma. Cancer Discov, 4(11), 1326-1341. doi:10.1158/2159-8290.CD-13-1037

Deshaies, R. J. (2015). Protein degradation: Prime time for PROTACs. Nat Chem Biol, 11(9), 634-635. doi:10.1038/nchembio.1887

Galeev, R., Baudet, A., Kumar, P., Rundberg Nilsson, A., Nilsson, B., Soneji, S., . . Larsson, J. (2016). Genomewide RNAi Screen Identifies Cohesin Genes as Modifiers of Renewal and Differentiation in Human HSCs. Cell Rep, 14(12), 2988-3000. doi:10.1016/j.celrep.2016.02.082

Guo, G., Sun, X., Chen, C., Wu, S., Huang, P., Li, Z., . . . Cai, Z. (2013). Whole-genome and whole-exome sequencing of bladder cancer identifies frequent alterations in genes involved in sister chromatid cohesion and segregation. Nat Genet, 45(12), 1459-1463. doi:10.1038/ng.2798

Hara, K., Zheng, G., Qu, Q., Liu, H., Ouyang, Z., Chen, Z., . . Yu, H. (2014). Structure of cohesin subcomplex pinpoints direct shugoshin-Wapl antagonism in centromeric cohesion. Nat Struct Mol Biol, 21(10), 864-870. doi:10.1038/nsmb.2880

Hill, V. K., Kim, J. S., \& Waldman, T. (2016). Cohesin mutations in human cancer. Biochim Biophys Acta, 1866(1), 1-11. doi:10.1016/j.bbcan.2016.05.002

Hu, B., Itoh, T., Mishra, A., Katoh, Y., Chan, K. L., Upcher, W., . . Nasmyth, K. (2011). ATP hydrolysis is required for relocating cohesin from sites occupied by its Scc2/4 loading complex. Curr Biol, 21(1), 12-24. doi:10.1016/j.cub.2010.12.004

Kim, G., Ison, G., McKee, A. E., Zhang, H., Tang, S., Gwise, T., . . Pazdur, R. (2015). FDA Approval Summary: Olaparib Monotherapy in Patients with Deleterious Germline BRCA-Mutated Advanced Ovarian 
Cancer Treated with Three or More Lines of Chemotherapy. Clin Cancer Res, 21(19), 4257-4261. doi:10.1158/1078-0432.CCR-15-0887

Kim, J. S., He, X., Orr, B., Wutz, G., Hill, V., Peters, J. M., . . Waldman, T. (2016). Intact Cohesion, Anaphase, and Chromosome Segregation in Human Cells Harboring Tumor-Derived Mutations in STAG2. PLoS Genet, 12(2), e1005865. doi:10.1371/journal.pgen.1005865

Kon, A., Shih, L. Y., Minamino, M., Sanada, M., Shiraishi, Y., Nagata, Y., . . Ogawa, S. (2013). Recurrent mutations in multiple components of the cohesin complex in myeloid neoplasms. Nat Genet, 45(10), 1232-1237. doi:10.1038/ng.2731

Lawrence, M. S., Stojanov, P., Mermel, C. H., Robinson, J. T., Garraway, L. A., Golub, T. R., . . Getz, G. (2014). Discovery and saturation analysis of cancer genes across 21 tumour types. Nature, 505(7484), 495501. doi:10.1038/nature12912

Leiserson, M. D., Vandin, F., Wu, H. T., Dobson, J. R., Eldridge, J. V., Thomas, J. L., . . Raphael, B. J. (2015). Pan-cancer network analysis identifies combinations of rare somatic mutations across pathways and protein complexes. Nat Genet, 47(2), 106-114. doi:10.1038/ng.3168

Losada, A. (2014). Cohesin in cancer: chromosome segregation and beyond. Nat Rev Cancer, 14(6), 389-393. doi:10.1038/nrc3743

Losada, A., Yokochi, T., Kobayashi, R., \& Hirano, T. (2000). Identification and characterization of SA/Scc3p subunits in the Xenopus and human cohesin complexes. J Cell Biol, 150(3), 405-416.

Mazumdar, C., Shen, Y., Xavy, S., Zhao, F., Reinisch, A., Li, R., . . Majeti, R. (2015). Leukemia-Associated Cohesin Mutants Dominantly Enforce Stem Cell Programs and Impair Human Hematopoietic Progenitor Differentiation. Cell Stem Cell, 17(6), 675-688. doi:10.1016/j.stem.2015.09.017

Mirza, M. R., Monk, B. J., Herrstedt, J., Oza, A. M., Mahner, S., Redondo, A., . . Investigators, E.-O. N. (2016). Niraparib Maintenance Therapy in Platinum-Sensitive, Recurrent Ovarian Cancer. $N$ Engl J Med, 375(22), 2154-2164. doi:10.1056/NEJMoa1611310

Mullenders, J., Aranda-Orgilles, B., Lhoumaud, P., Keller, M., Pae, J., Wang, K., . . Aifantis, I. (2015). Cohesin loss alters adult hematopoietic stem cell homeostasis, leading to myeloproliferative neoplasms. $J$ Exp Med, 212(11), 1833-1850. doi:10.1084/jem.20151323

Murayama, Y., \& Uhlmann, F. (2014). Biochemical reconstitution of topological DNA binding by the cohesin ring. Nature, 505(7483), 367-371. doi:10.1038/nature12867

Oza, A. M., Cibula, D., Benzaquen, A. O., Poole, C., Mathijssen, R. H., Sonke, G. S., . . Friedlander, M. (2015). Olaparib combined with chemotherapy for recurrent platinum-sensitive ovarian cancer: a randomised phase 2 trial. Lancet Oncol, 16(1), 87-97. doi:10.1016/S1470-2045(14)71135-0

Peters, J. M., \& Nishiyama, T. (2012). Sister chromatid cohesion. Cold Spring Harb Perspect Biol, 4(11). doi:10.1101/cshperspect.a011130

Pezzi, N., Prieto, I., Kremer, L., Perez Jurado, L. A., Valero, C., Del Mazo, J., . . Barbero, J. L. (2000). STAG3, a novel gene encoding a protein involved in meiotic chromosome pairing and location of STAG3related genes flanking the Williams-Beuren syndrome deletion. FASEB J, 14(3), 581-592.

Prieto, I., Suja, J. A., Pezzi, N., Kremer, L., Martinez, A. C., Rufas, J. S., \& Barbero, J. L. (2001). Mammalian STAG3 is a cohesin specific to sister chromatid arms in meiosis I. Nat Cell Biol, 3(8), 761-766. doi:10.1038/35087082

Remeseiro, S., Cuadrado, A., Carretero, M., Martinez, P., Drosopoulos, W. C., Canamero, M., . . Losada, A. (2012). Cohesin-SA1 deficiency drives aneuploidy and tumourigenesis in mice due to impaired replication of telomeres. EMBO J, 31(9), 2076-2089. doi:10.1038/emboj.2012.11

Solomon, D. A., Kim, J. S., Bondaruk, J., Shariat, S. F., Wang, Z. F., Elkahloun, A. G., . . Waldman, T. (2013). Frequent truncating mutations of STAG2 in bladder cancer. Nat Genet, 45(12), 1428-1430. doi:10.1038/ng.2800

Solomon, D. A., Kim, T., Diaz-Martinez, L. A., Fair, J., Elkahloun, A. G., Harris, B. T., . . Waldman, T. (2011). Mutational inactivation of STAG2 causes aneuploidy in human cancer. Science, 333(6045), 10391043. doi:10.1126/science.1203619 
Sumara, I., Vorlaufer, E., Gieffers, C., Peters, B. H., \& Peters, J. M. (2000). Characterization of vertebrate cohesin complexes and their regulation in prophase. J Cell Biol, 151(4), 749-762.

Taylor, C. F., Platt, F. M., Hurst, C. D., Thygesen, H. H., \& Knowles, M. A. (2014). Frequent inactivating mutations of STAG2 in bladder cancer are associated with low tumour grade and stage and inversely related to chromosomal copy number changes. Hum Mol Genet, 23(8), 1964-1974. doi:10.1093/hmg/ddt589

Thota, S., Viny, A. D., Makishima, H., Spitzer, B., Radivoyevitch, T., Przychodzen, B., . . Maciejewski, J. P. (2014). Genetic alterations of the cohesin complex genes in myeloid malignancies. Blood, 124(11), 1790-1798. doi:10.1182/blood-2014-04-567057

Tirode, F., Surdez, D., Ma, X., Parker, M., Le Deley, M. C., Bahrami, A., ... the International Cancer Genome, C. (2014). Genomic landscape of Ewing sarcoma defines an aggressive subtype with co-association of STAG2 and TP53 mutations. Cancer Discov, 4(11), 1342-1353. doi:10.1158/2159-8290.CD-14-0622

Toth, A., Ciosk, R., Uhlmann, F., Galova, M., Schleiffer, A., \& Nasmyth, K. (1999). Yeast cohesin complex requires a conserved protein, $\mathrm{Eco} 1 \mathrm{p}(\mathrm{Ctf7})$, to establish cohesion between sister chromatids during DNA replication. Genes Dev, 13(3), 320-333.

Viny, A. D., Ott, C. J., Spitzer, B., Rivas, M., Meydan, C., Papalexi, E., ... Levine, R. L. (2015). Dose-dependent role of the cohesin complex in normal and malignant hematopoiesis. J Exp Med, 212(11), 18191832. doi:10.1084/jem.20151317

Walter, M. J., Shen, D., Ding, L., Shao, J., Koboldt, D. C., Chen, K., . . . Graubert, T. A. (2012). Clonal architecture of secondary acute myeloid leukemia. N Engl J Med, 366(12), 1090-1098. doi:10.1056/NEJMoa1106968 


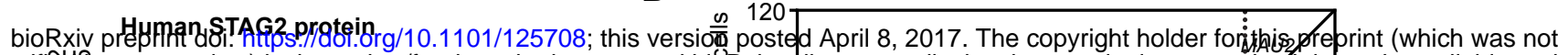
certifiad by peer review) is the author/funder, who has granted bi\&Rxiv a license to display the preprint in perpetenty It is made available under

至

\begin{tabular}{|l|l|l|l}
\hline STAG & SCD & \\
\hline
\end{tabular}

C

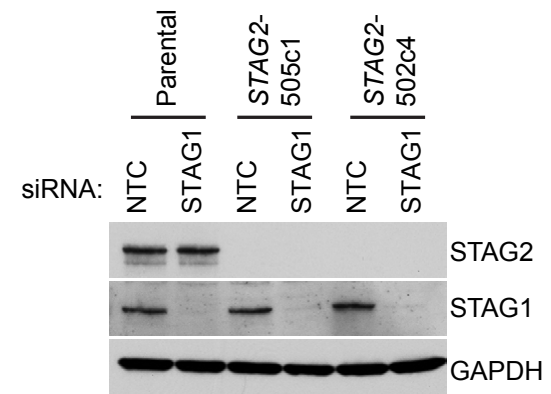

HCT 116

D

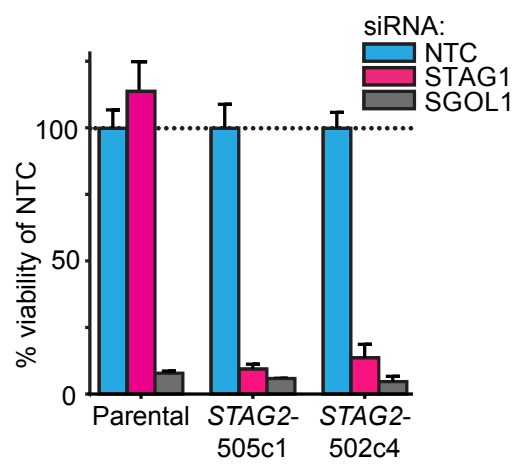

E

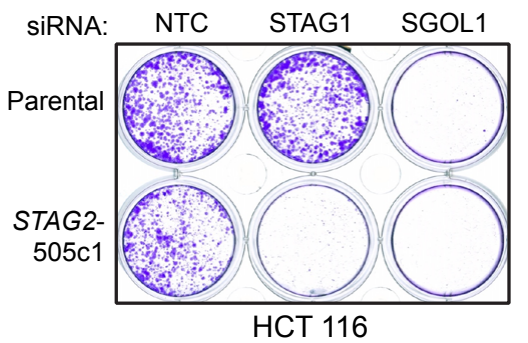
aCC-BY $4 \$$ Intertational license

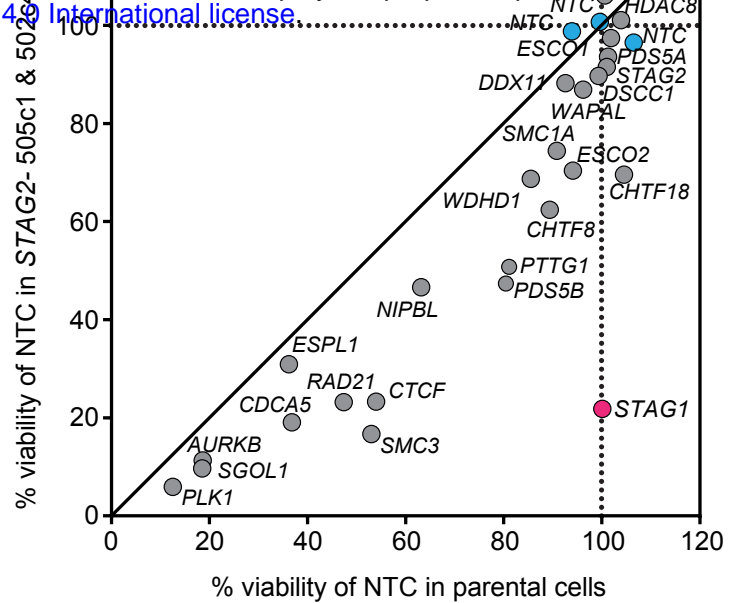

Cas9- sgRNA-

F GFP mCherry Negative selection

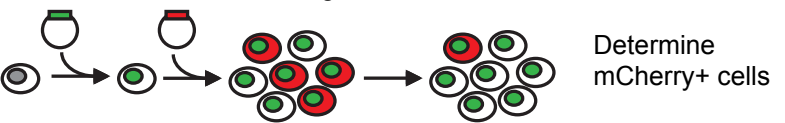

口Day 4 DDay 7 Day 14 Parental

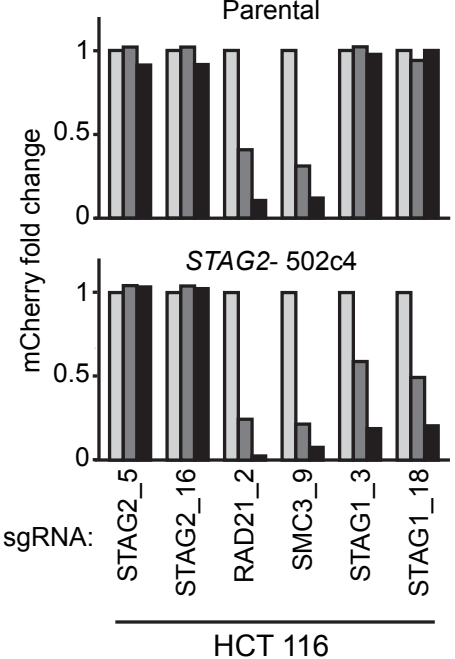

口Day 1 DDay 7 Day 14 Parental
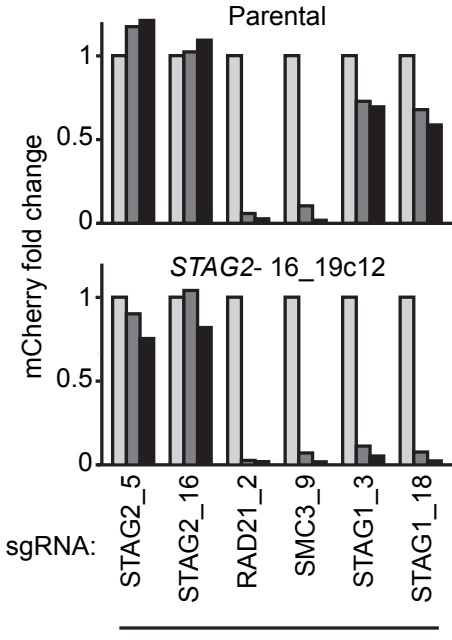

KBM-7

Figure 1. Identification of STAG1 as a synthetic lethal interaction of STAG2 mutated cells. (A) Engineering of an isogenic HCT 116 cell model by CRISPR/Cas9-mediated inactivation of STAG2. The position of the sgRNAs used to create deleterious insertion and deletion mutations in the STAG2 coding sequence is indicated. (B) Parental HCT 116 cells and two STAG2 mutant clones (STAG2-) were subjected to an siRNA screen. Pools of 4 siRNA duplexes targeting 25 known cohesin subunits and regulators were transfected into the three cell lines. Cell viability was measured seven days after transfection. Following normalization to non-target control (NTC) values, the average cell viability of siRNA pools in parental HCT 116 cells and two STAG2- clones was plotted against each other ( $\mathrm{n}=2$ or more independent experiments with 2 biological repeats each). (C) HCT 116 parental cells and STAG2- clones were transfected with the indicated siRNAs. Protein lysates were prepared 72 hours after transfection and analyzed by immunoblotting. (D) Cell viability was assessed eight days after siRNA transfection using a metabolic assay ( $n=4$ biological repeats, error bars denote standard deviation) and $(E)$ with crystal violet staining. $(\mathbf{F})$ Cas9-GFP expressing isogenic parental and STAG2- HCT 116 and KBM-7 cells were transduced with a lentivirus encoding $\mathrm{mCherry}$ and sgRNAs targeting the indicated genes. The percentage of mCherry-positive cells was determined over time by flow cytometry and normalized to the fraction of mCherry-positive cells at the first measurement and sequentially to a control sgRNA ( $n=1$ experimental replicate). 


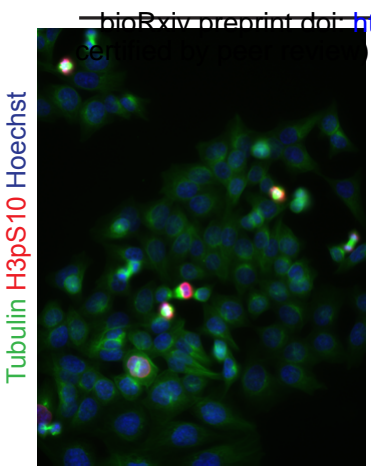

Parental

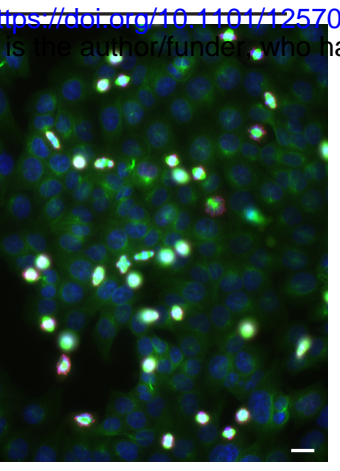

STAG2- 505c1

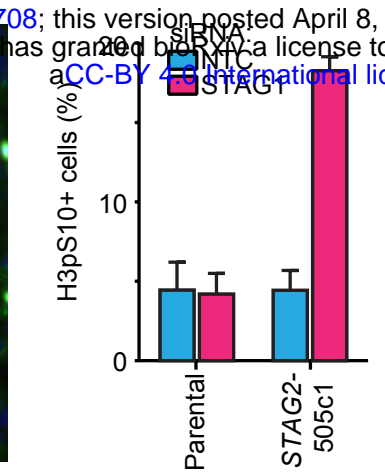

م

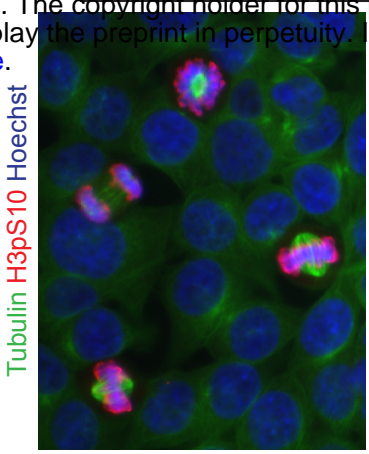

Parental

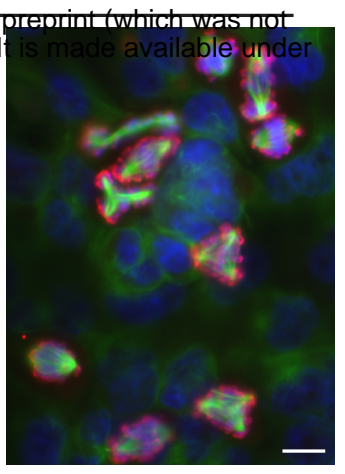

STAG2- 505c1
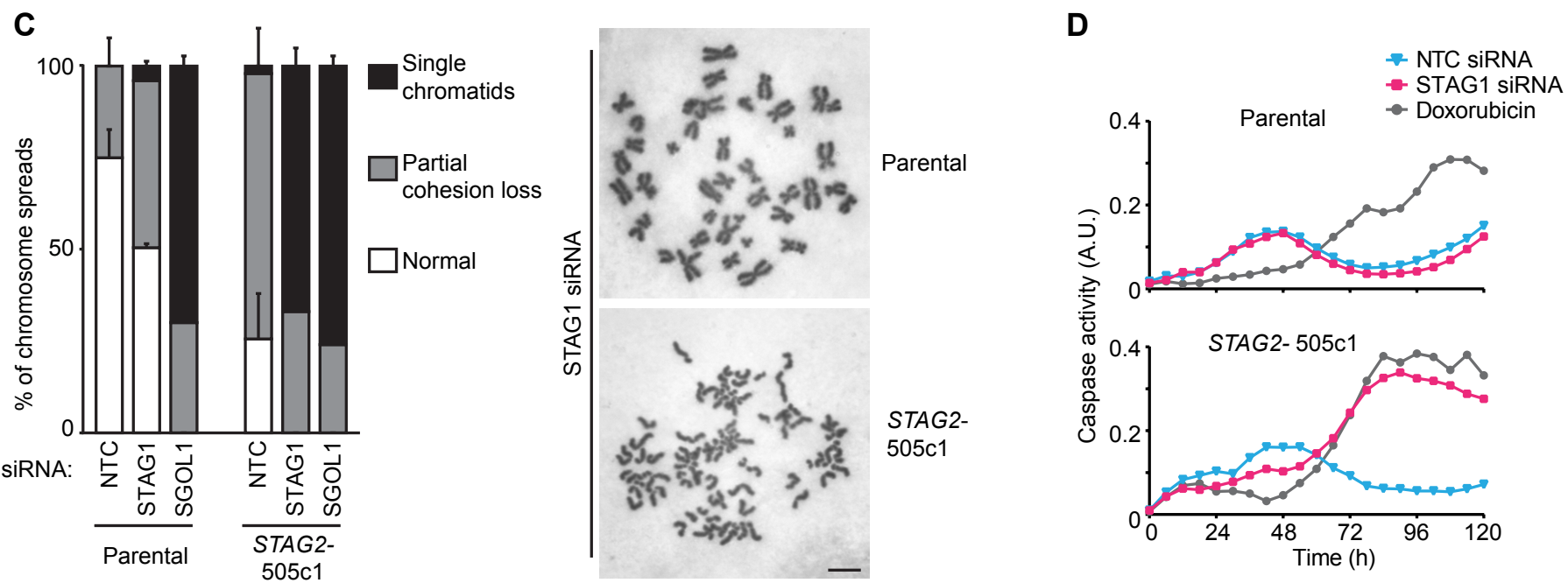

Figure 2. Loss of STAG1 function causes severe mitotic defects, abrogates sister chromatid cohesion and triggers apoptosis in STAG2- but not parental HCT 116 cells. (A) Parental and STAG2- 505c1 HCT 116 were transfected with NTC and STAG1 siRNA duplexes. Immunofluorescence analysis was performed 72 hours after transfection to determine the mitotic index by scoring the fraction of phosphoSer10-positive (H3pS10+) cells ( $n \geq 1323$ cells, error bars denote standard deviation of three independent experiments), and (B) to investigate mitotic spindle geometry and chromosome alignment. Scale bars, $20 \mu \mathrm{m}$. (C) Giemsa-stained mitotic chromosome spreads were prepared 48 hours after transfection of parental and STAG2- HCT 116 cells with the indicated siRNA duplexes. The status of sister chromatid cohesion of individual metaphase spreads was categorized into normal, partial loss of cohesion or single chromatid phenotypes ( $n=100$ spreads, error bars denote standard deviation of two independently analyzed slides). Scale bar, $10 \mu \mathrm{m}$. (D) Caspase activity was tracked over time using a live-cell caspase 3/7 substrate cleavage assay in parental and STAG2-505c1 HCT 116 cells after transfection with the indicated siRNAs or after treatment with $0.3 \mu \mathrm{M}$ doxorubicin at $\mathrm{t}=0$ hours $(\mathrm{n}=2$ independent experiment with 4 biological repeats for NTC and STAG1 siRNA each and 1 biological repeat for doxorubicin each). 


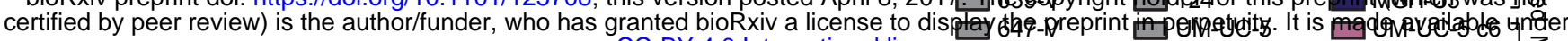

STAG2 positive

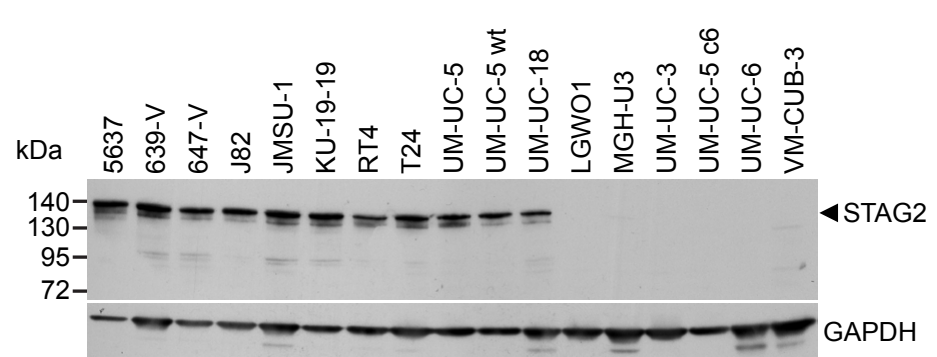

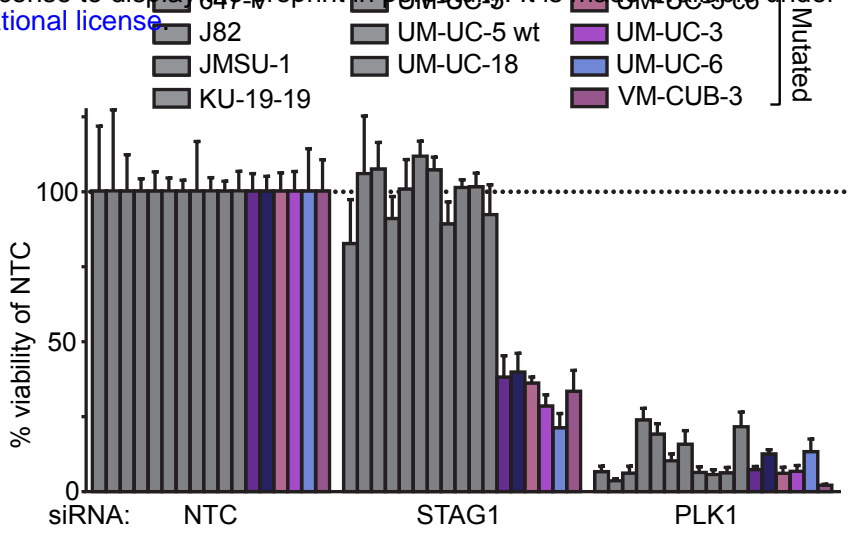

C

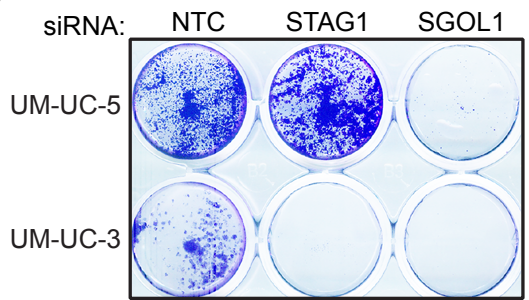

D

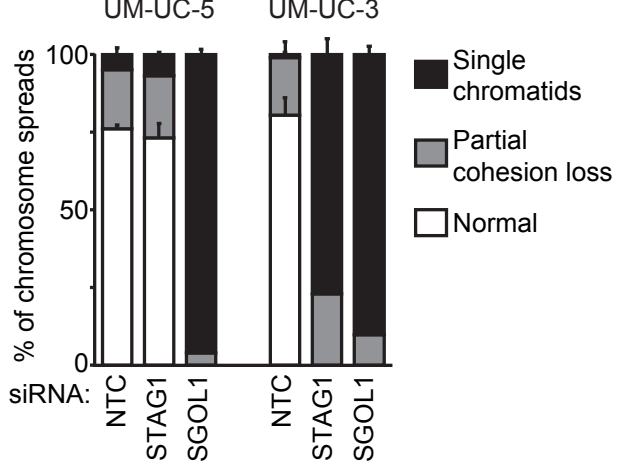

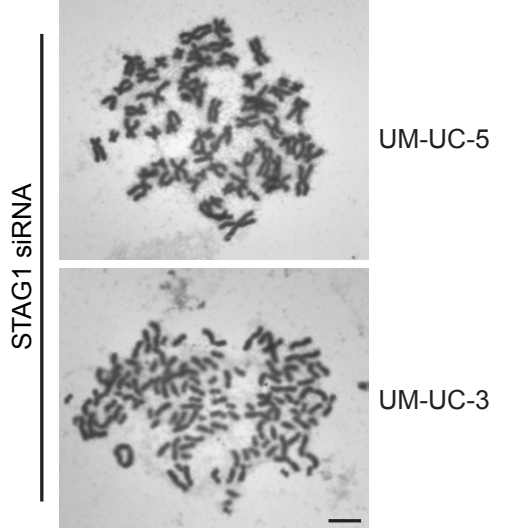

E

Ewing sarcoma

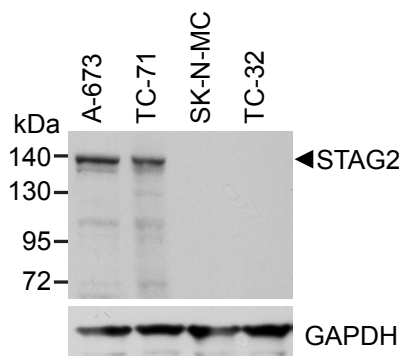

$\mathbf{F}$

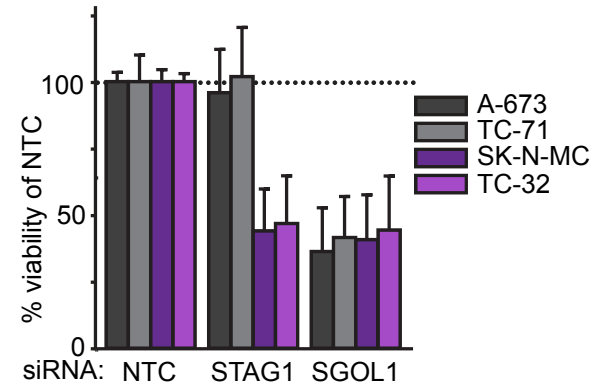

G Restoration of STAG2 expression

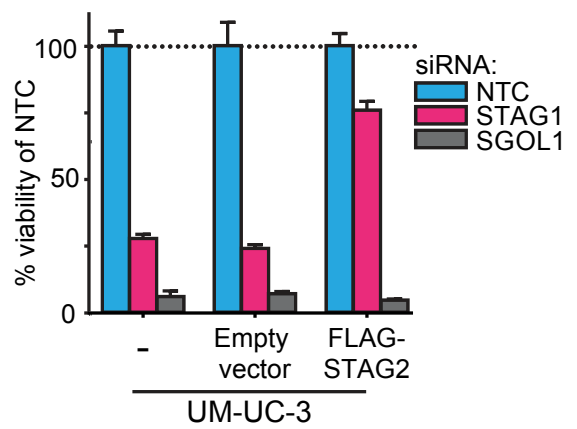

Figure 3. The synthetic lethal interaction between STAG1 and STAG2 is manifested in disease-relevant bladder cancer and Ewing sarcoma cell lines. (A) The indicated bladder cancer cell lines were analyzed for STAG2 expression by immunoblotting. (B) The indicated bladder cancer cell lines were transfected with NTC, STAG1 and PLK1 siRNA duplexes. Viability was measured seven or ten days after transfection and normalized to the viability of NTC siRNA transfected cells $(n=2$ independent experiments with 5 biological repeats each, error bars denote standard deviation). (C) STAG2 wild-type UM-UC-5 and STAG2 mutated UM-UC-3 cells were transfected with NTC, STAG1 and SGOL1 siRNA duplexes. Colony formation was analyzed seven days after transfection by crystal violet staining. (D) 72 hours after siRNA transfection into UM-UC-5 and UM-UC-3 cells, Giemsa-stained chromosome spreads were prepared and analyzed for sister chromatid cohesion phenotypes $(n=100$ spreads, error bars denote standard deviation of two independently analyzed slides). (E) The indicated Ewing sarcoma cell lines were analyzed for STAG2 protein expression by immunoblotting. (F) The indicated Ewing sarcoma cell lines were transfected with NTC, STAG1 and SGOL1 siRNA duplexes. Viability was measured six days after transfection and normalized to the viability of NTC siRNA transfected cells $(n=3$ independent experiments with 3 biological replicates each, error bars denote standard deviation). (G) STAG2 mutated UM-UC-3 cells were transduced with a lentivirus encoding an siRNA-resistant FLAG-STAG2 transgene. Stably selected cell pools were subsequently transfected with NTC, STAG1 or SGOL1 siRNA duplexes. Viability was measured seven days after transfection and normalized to the viability of NTC siRNA transfected cells $(n=4$ biological replicates, error bars denote standard deviation). 
Exon:8 Rxiv preprint doi: $h$ ttps://doi.org/10.11 \$9R/NA 508; this wersion posted April 8, 2017. The copyright holder for this preprint (which was not

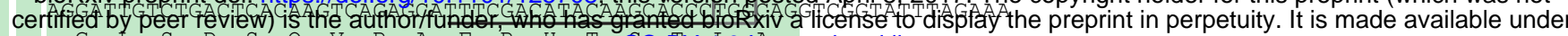
G L S D S Q V R A F R H T aEC-BY 4.0 IAternational license.

Exon $9 \quad$ sgRNA 505

AATAAAATGATTGGAAAACGAGCAATGAGAGGCTAGAACTCCTGCTACAAAAGCGGAAGAGGTAAA

$\begin{array}{llllllllllllllllllllll}N & K & M & I & G & K & R & A & N & E & R & L & E & L & L & L & Q & K & R & K & E\end{array}$

253

Exon 8

GATAGTGGAGATTATCCACTTACCATGGCTGGTCCTCAGTGGAAGAAGTTCAAATCCAGTTTTTGTGA

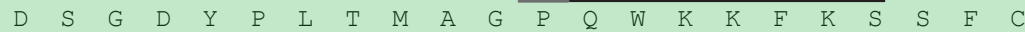
155

Exon $9 \quad$ sgRNA STAG2_19

AATAAAATGATTGGAAAAGAGCCAATGAGAGGCTAGAACTCCTGCTACAAAAGCGGAAAGAGGTAAA

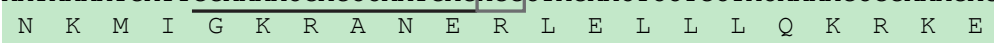

253

B

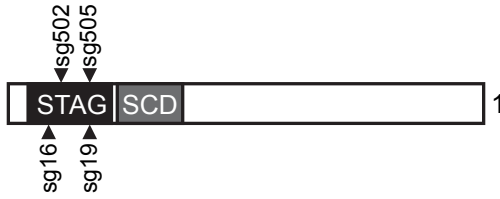

STAG

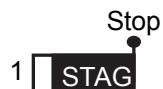

240 aa

178 aa

STA

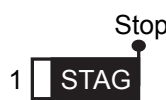

Stop

STAG

STAG

1268 aa

260 aa

261 aa
STAG2- 505c1

p.M255ins ${ }^{*}$ random sequence insertion resulting in stop codon at 261

HCT116 STAG2- 502c4

p.T220fs ${ }^{*} 2210 \mathrm{bp}$ insertion resulting in stop codon at 241

KBM-7 STAG2-16_19c12 (single allele)

p.P166fs*14 10 bp deletion resulting in stopcodon at 179

p.N261fs ${ }^{*} 10$ bp deletion resulting in an immediate stop at 261

UM-UC-5 STAG2- 505c6:

Allele 1: p.E262* $1 \mathrm{bp}$ insertion resulting in nonsense mutation at 262

Allele 2: p.R261fs*4 1 bp deletion resulting in stop codon at 264
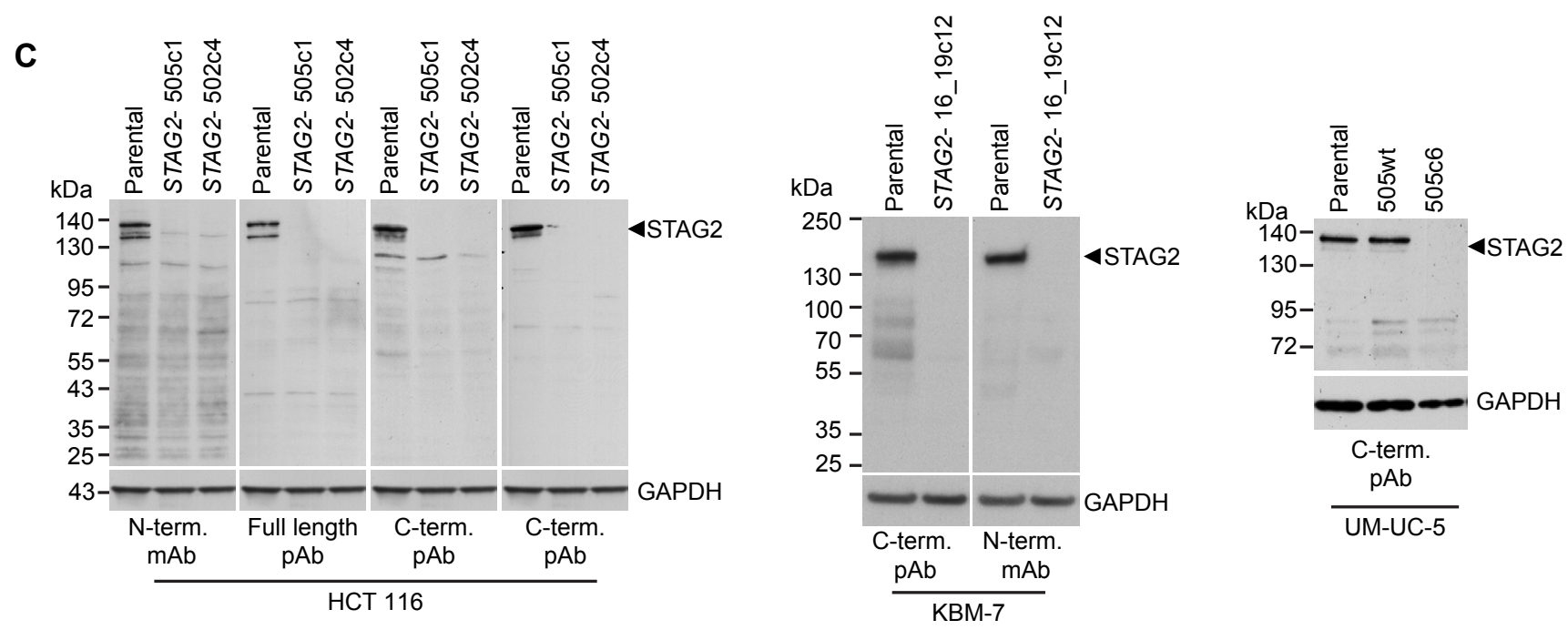

Figure supplement 1. Characterization of CRISPR/Cas9-generated STAG2 mutated clones used in this study. (A) Four different sgRNAs co-expressed with Cas9 from an all-in-one plasmid or a lentiviral vector were used to generate deleterious frameshift insertions or deletion mutations (indels) in STAG2 coding exons. sgRNAs sg502 and sg16 target exon 8 of STAG2, while sgRNAs sg505 and sg19 target exon 9 of the gene. Cognate sgRNA target sequences are underlined. Associated protospacer adjacent motifs (PAMs) are marked by boxes. The predicted Cas9 cleavage sites are marked by triangles. (B) CRISPR/Cas9-generated STAG2 indels in HCT 116, KBM-7 and UM-UC-5 cell clones as detected by Sanger sequencing. STAG2 is located on the $X$ chromosome. Therefore, only one allele needed to be inactivated in HCT 116 (male) and KBM-7 (near-haploid) cells, while two alleles had to be inactivated in UM-UC-5 (female) cells. (C) Protein lysates prepared from the indicated parental and mutant clones were analyzed for STAG2 protein expression by immunoblotting using antibodies directed against different STAG2 epitopes. 
A

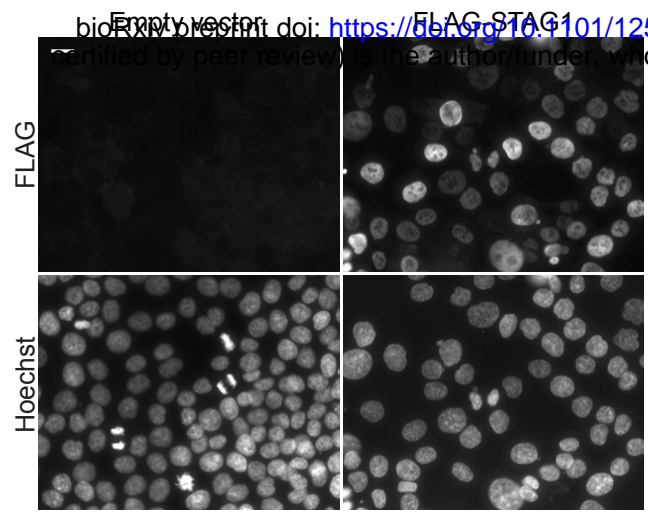

HCT 116 STAG2- 505c1

5708; this versionposted April \&, 2017. The copyright holder for this preprint (which was not

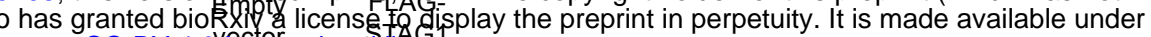
aCC-BY 4.0vergternationallicense.

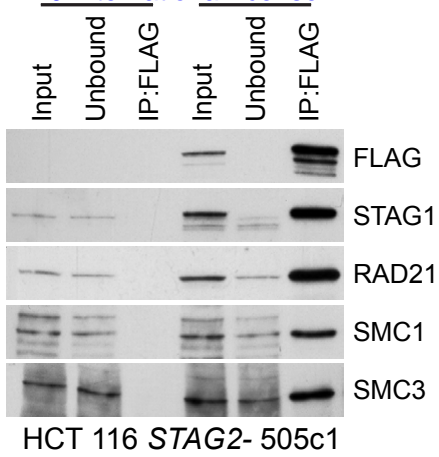

C

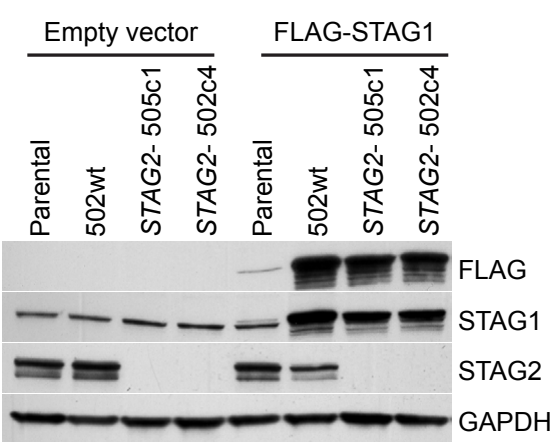

HCT 116

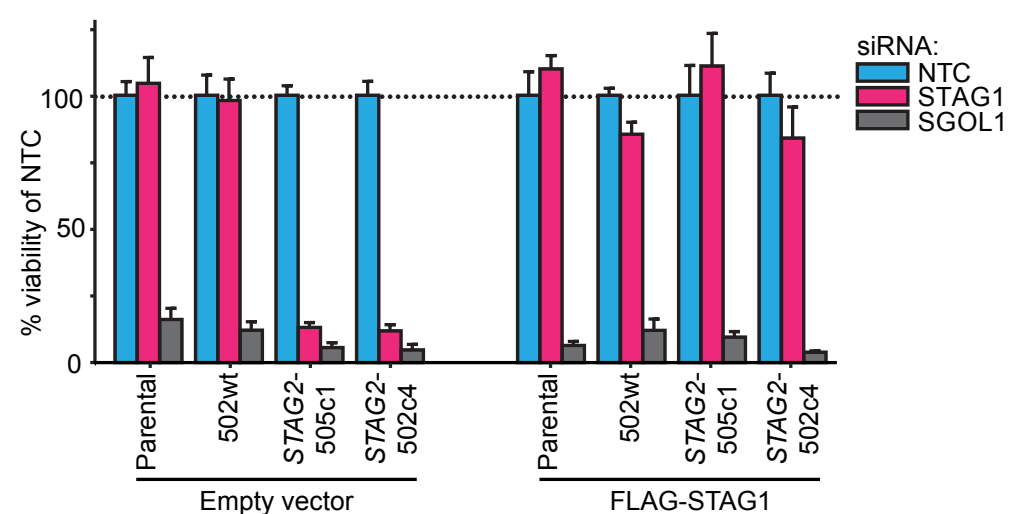

Empty vector

FLAG-STAG1

Figure supplement 2. Rescue of the synthetic lethal interaction between STAG1 and STAG2 by expression of an siRNA-resistant FLAG-STAG1 transgene. HCT 116 parental cells, a STAG2 wild-type clone (502wt), and two STAG2- clones (505c1 and 502c4) were transduced with a lentivirus encoding no transgene (empty vector) or an siRNA-resistant and 3xFLAG-tagged STAG1 transgene (FLAG-STAG1). Stably selected cell pools were used for the analysis. (A) Immunofluorescence analysis of FLAG-STAG1 transgene expression and nuclear localization in HCT 116 STAG2- 505c1 cells. Scale bar, $20 \mu \mathrm{m}$. (B) Protein extracts prepared from HCT 116 STAG2- 505c1 cells expressing no transgene (empty vector) or a FLAG-STAG1 transgene were subjected to anti-FLAG immunoprecipitation. The input, unbound and precipitated fractions were analyzed by immunoblotting. Co-precipitation of cohesin subunits was only detected in FLAG-STAG1 expressing cells indicating specific incorporation of the transgenic protein into the cohesin complex. (C) Protein extracts prepared from the indicated cell lines that were transduced with an empty vector or a FLAG-STAG1 transgene were analyzed by immunoblotting (left panel) and transfected with NTC, STAG1 and SGOL1 siRNA duplexes (right panel). Cell viability was measured seven days after transfection and is plotted normalized to the viability of NTC siRNA transfected cells ( $n \geq 5$ biological repeats, error bars denote standard deviation). 
B

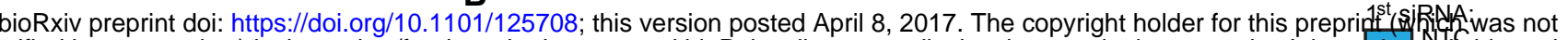

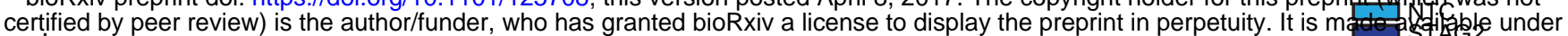

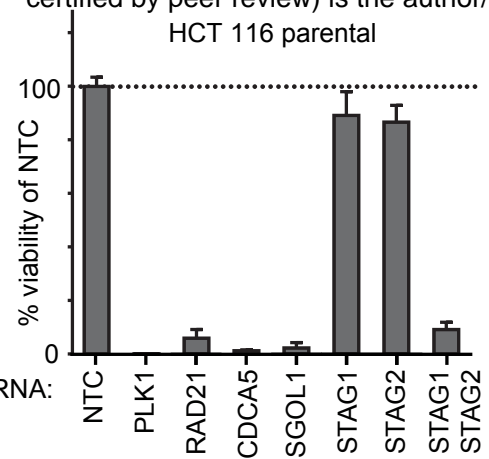
aCC-BY 4.0 International license.

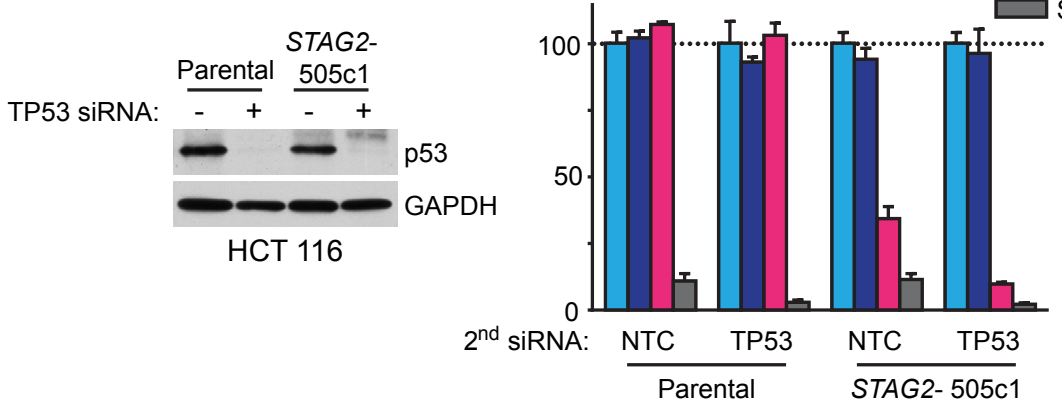

Figure supplement 3. Double depletion experiments confirm STAG1/STAG2 synthetic lethality and indicate p53 independence thereof. (A) HCT 116 parental cells were co-transfected with NTC siRNA and siRNA duplexes targeting one of the following genes: NTC, PLK1, RAD21, CDCA5, SGOL1, STAG1 or STAG2. HCT 116 parental cells were also co-transfected with siRNA duplexes targeting STAG1 and STAG2. Cell viability was determined eight days after transfection and is plotted normalized to cell viability of NTC siRNA-transfected cells ( $\mathrm{n}=3$ biological repeats, error bars denote standard deviation). (B) Parental HCT 116 cells and STAG2- 505c1 cells were transfected with NTC (-) or TP53 (+) siRNA duplexes. Protein extracts were prepared four days after transfection and analyzed by immunoblotting (left panel). Parental HCT 116 cells and STAG2- 505c1 cells were co-transfected with the indicated siRNA duplexes (right panel). Cell viability was determined eight days after transfection and is plotted normalized to the cell viability of NTC+NTC or NTC+TP53 siRNA-co-transfected cells ( $n=3$ biological repeats, error bars denote standard deviation). 
bioRxiv preprint geib. bt:\$s://doi.org/10.1101/12570

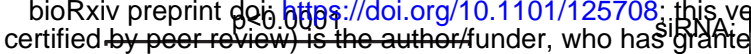

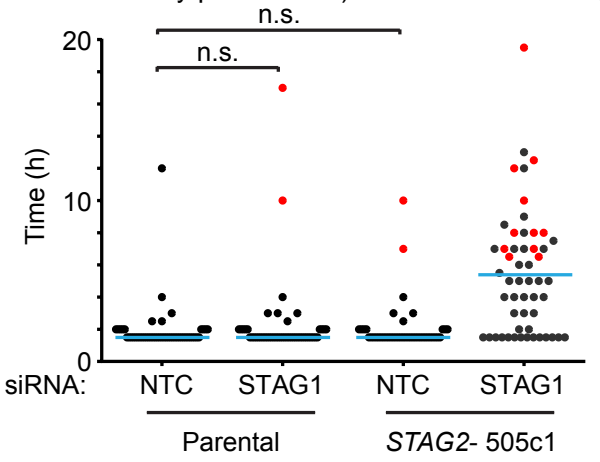

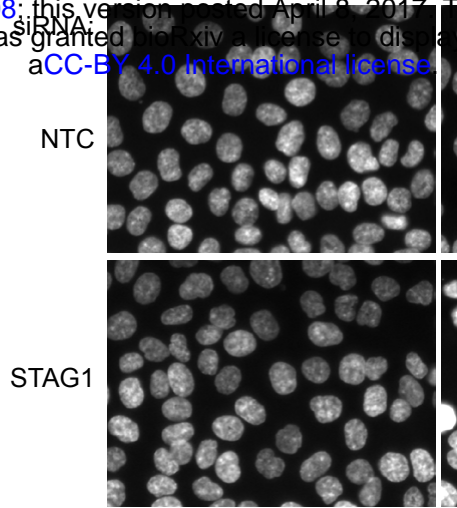

Parental
Hoechst

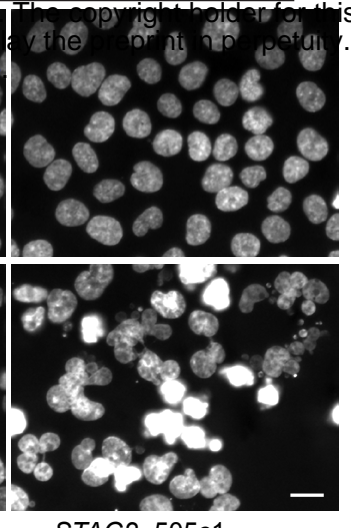

STAG2- 505c1

preprint (which was not It is-made ayłajiaple under

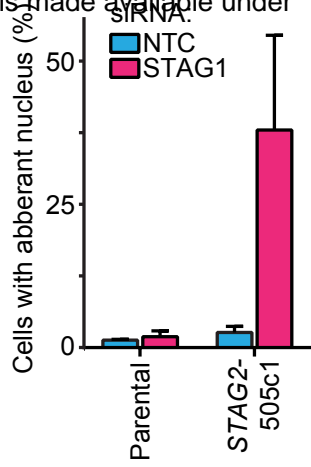

Figure supplement 4. The depletion of STAG1 triggers severe mitotic defects in STAG2 mutated but not parental HCT 116 cells. (A) Parental and STAG2- 505c1 HCT 116 were transfected with NTC and STAG1 siRNA duplexes. Cells were tracked from 0.5 to 72 hours (imaging interval $30 \mathrm{~min}$ ) after transfection by bright-field live-cell imaging. The duration of mitosis (time elapsed from mitotic cell rounding to anaphase onset) and fate of individual cells were determined ( $n \geq 43$ cells). The duration of mitosis of individual cells is plotted. Blue lines denote mean, red dots denote cells that died in mitosis. Significance levels were quantified using unpaired t test. (B) Parental and STAG2505c1 HCT 116 were transfected with NTC and STAG1 siRNA duplexes, fixed and stained with Hoechst 72 hours after transfection. Nuclei were scored for aberrant size $(>20 \mu \mathrm{m}$ ) or morphology (multi-nucleated cells and cells with polylobed nuclei; $\mathrm{n} \geq 612$ nuclei, error bars denote standard deviation between two independent experiments). 


\section{A HCT 116 STAG2 cancer mutations}

B

C

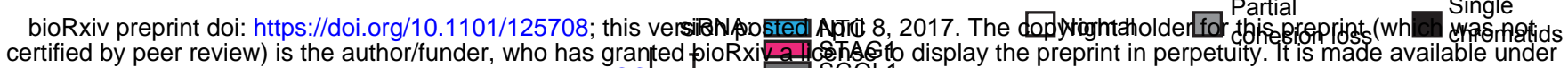
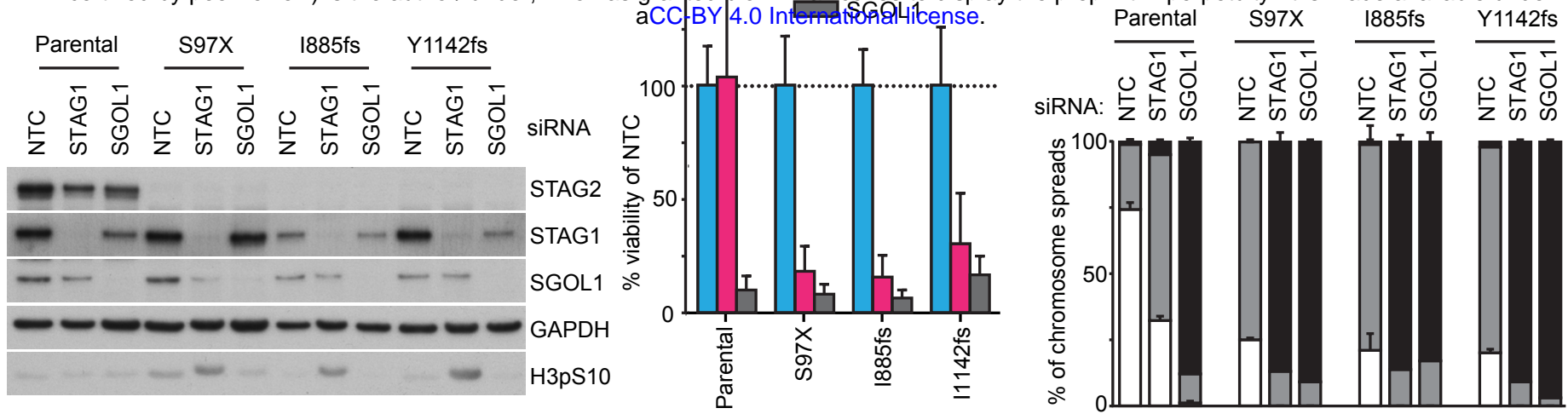

Figure supplement 5. Patient-derived STAG2 mutations cause STAG1 dependency in engineered isogenic HCT 116 cells. HCT 116 cell lines engineered to harbor the indicated deleterious patient-derived STAG2 mutations were transfected with NTC, STAG1 and SGOL1 siRNA duplexes. A, Protein extracts were prepared 48 hours after transfection and analyzed by immunoblotting. B, Cell viability was measured seven days after siRNA transfection and plotted normalized to the viability of NTC-transfected cells ( $n=4$ independent experiments with 5 biological repeats each, error bars denote standard deviation). C, Sister chromatid cohesion phenotypes were analyzed in Giemsa-stained mitotic chromosome spreads that were prepared 48 hours after siRNA transfection $(n=100$ chromosome spreads, error bars denote standard deviation between two independently analyzed slides). 


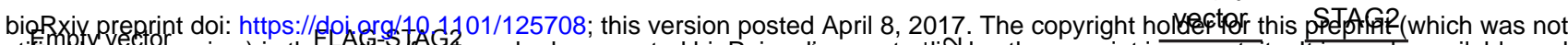
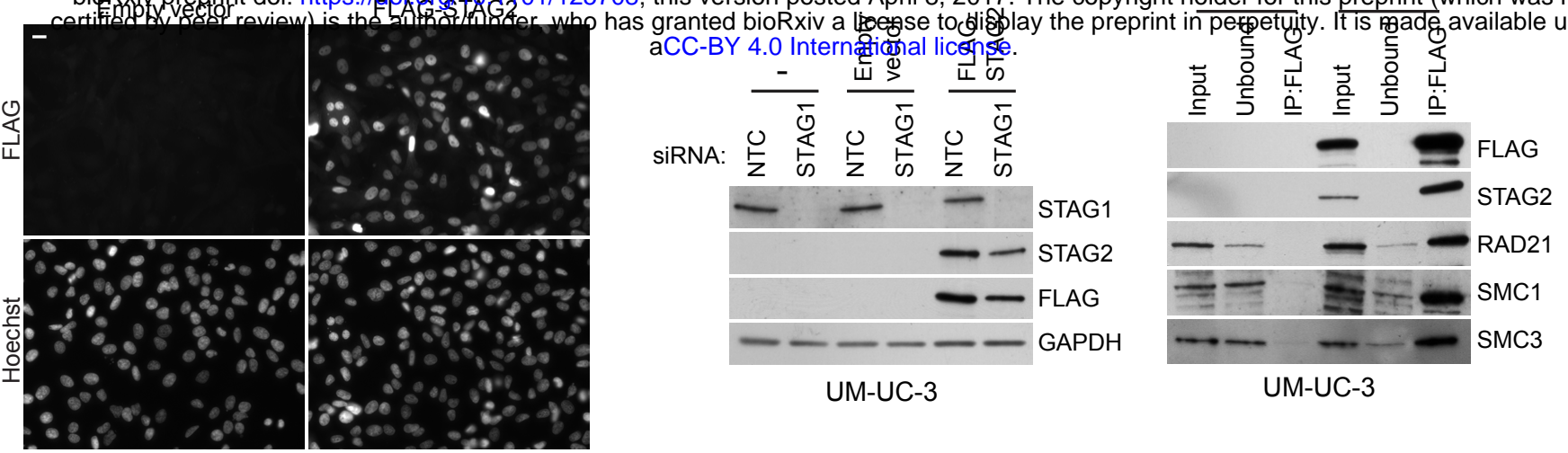

UM-UC-3

D

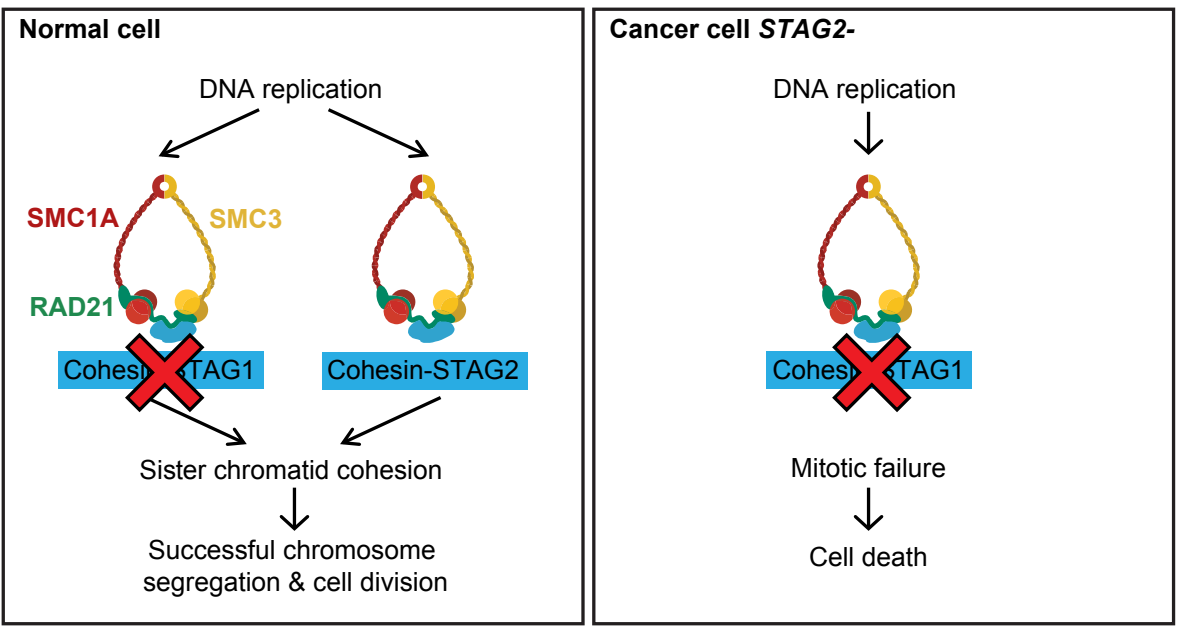

Figure supplement 6. Restoration of STAG2 protein expression in UM-UC-3 bladder cancer cells. STAG2-deficient UM-UC-3 cells were transduced with lentiviral particles encoding no transgene (empty vector) or a 3xFLAG-tagged STAG2 transgene (FLAG-STAG2). Stable selected cell pools were used for further analysis. (A) Expression and nuclear localization of the transgenic FLAG-STAG2 protein was assayed by immunofluorescence microscopy. (B) Non-transduced UM-UC-3 cells, UM-UC-3 cells transduced with an empty vector and UM-UC-3 cells transduced with a FLAG-STAG2 transgene were transfected with NTC or STAG1 siRNA duplexes. Protein lysates prepared 72 hours after siRNA transfection were analyzed by immunoblotting. (C) Protein extracts prepared from UM-UC-3 cells expressing no transgene (empty vector) or a FLAG-STAG2 transgene were subjected to anti-FLAG immunoprecipitation. The input, unbound and precipitated fractions were analyzed by immunoblotting. Co-precipitation of cohesin subunits was only detected in FLAG-STAG2 expressing cells indicating successful incorporation of the transgenic STAG2 protein into the cohesin complex. (D) Model for the synthetic lethal interaction between STAG1 and STAG2. In wild-type cells, both cohesin-STAG1 and cohesin-STAG2 complexes redundantly contribute to sister chromatid cohesion and successful cell division. Loss of STAG1 is tolerated in these cells as cohesin-STAG2 complexes alone suffice to support sister chromatid cohesion for cell division. In cancer cells in which STAG2 is mutationally or transcriptionally inactivated, sister chromatid cohesion is now entirely dependent on cohesin-STAG1 complexes. Inactivation of STAG1 in STAG2 mutated cells therefore results in a loss of sister chromatid cohesion followed by mitotic failure and cell death. 